\title{
ESTUDO DE CASO APLICANDO MODELO PARA IDENTIFICAÇÃO DE POTENCIAIS GERADORES DE INTANGÍVEIS
}

\section{Rodney Wernke}

Professor Doutor do Curso de Administração da Universidade do Sul de Santa Catarina - SC

E-mail: rodneyw@unisul.br

\section{Antonio Cezar Bornia}

Professor Doutor do Programa de Pós-graduação em Engenharia de Produção

da Universidade Federal de Santa Catarina - SC

E-mail: cezar@inf.ufsc.br

\section{RESUMO}

Relata estudo de caso em que foi aplicado o modelo Mapa para Identificação de Potenciais Geradores de Intangíveis. Após mencionar resumidamente a ferramenta utilizada, apresentam-se os procedimentos seguidos para implementar tal modelo numa empresa industrial, evidenciando os passos seguidos, as análises realizadas, os resultados alcançados e as limitações inerentes.

Palavras-chave: Ativos Intangíveis, Estudo de Caso.

\section{ABSTRACT}

This article reports on a case study which applied the model called Map for the Identification of Potential Intangible Asset Generators. After a summarized description of the applied tool, we present the procedures followed to implement such a model in an industrial company, disclosing the steps that were taken, the analyses carried out, obtained results and inherent limitations.

Keywords: Intangible Assets, Case Study. 


\section{CONSIDERAÇÕES INICIAIS}

A partir da última década do século passado têm se tornado mais relevantes os aspectos intangíveis de uma organização, em detrimento de seus ativos tangíveis (como máquinas, prédios, veículos etc). Isso deriva da modernização da economia mundial, que passou a considerar fatores como capacidade de inovação, conhecimento e perícia do quadro de funcionários, habilidades de negociação, localização geográfica, produtividade, qualidade, dentre outros itens, como indicadores da competitividade das empresas. Em função disso, referido tema vem despertando a atenção de estudiosos e pesquisadores de várias áreas e na seara contábil diversos artigos já foram publicados a respeito. Mesmo com divergências conceituais entre os autores, resta evidente a importância que esse fator assume nas empresas que competem em mercados acirrados, no contexto econômico atual, notadamente no que tange à avaliação das mesmas.

Entretanto, a relação dos ativos intangíveis com a área contábil ainda não está totalmente esclarecida. As demonstrações contábeis, por serem elaboradas segundo os princípios e convenções que norteiam a ciência contábil, têm dificuldades para expressar os componentes intangíveis das entidades. Assim, diversos pesquisadores apresentaram métodos que se propõem a contribuir com a mensuração desse tipo de ativo, tentando minimizar os efeitos nocivos do seu não conhecimento por parte dos investidores.

Nessa direção, este artigo objetiva relatar estudo de caso em que foi aplicado um modelo que possibilitou identificar potenciais geradores de intangíveis. Para tanto, inicialmente comenta-se acerca dos Ativos Intangíveis no contexto atual. Na seqüência apresenta-se, resumidamente, o modelo utilizado e são descritos os procedimentos seguidos no estudo efetuado. Por último, são evidenciadas as conclusões oriundas e as limitações detectadas na aplicação do modelo numa empresa industrial.

\section{OS ATIVOS INTANGÍVEIS NO CONTEXTO ATUAL}

Os gestores têm na Contabilidade uma importante fonte de informações, desde que a mesma esteja projetada no sentido de ofertar informes adequados aos seus usuários, segundo Leone (1996). Entretanto, conforme Silva et al. (1999), no que tange à sua função de oferecer informações quanto ao valor patrimonial da empresa e seu confronto com o valor de mercado das entidades, a Contabilidade tem sido criticada pelas dificuldades que encontra em atender as necessidades dos administradores e demais usuários.

Nesse sentido, Johnson e Kaplan (1996, p.197) afirmam que "o fundamento intelectual dos sistemas de contabilidade gerencial na maioria das organizações atuais ficou ultrapassado [...]", principalmente se considerado que há um acirramento maior da competitividade em termos internacionais, que novos formatos organizacionais são empregados e que a área tecnológica se desenvolve cada vez mais rápido e influi decisivamente no ambiente empresarial. Em função disso, os administradores têm uma necessidade crescente de buscar novas abordagens que possam servir para monitorar esta nova realidade com maior pertinência.

As novas abordagens referidas visam atender uma das funções principais da Contabilidade que é ofertar informações imprescindíveis à adequada gestão das entidades. Tal função vinha sendo atendida de forma mais ou menos eficiente até há pouco tempo, enquanto os administradores estavam voltados ao gerenciamento das transações envolvendo valores relacionados aos ativos tangíveis das empresas, como estoques, veículos, prédios, disponibilidades financeiras e outros.

Contudo, Catelli e Santos (2001) ressaltam que há tempos são proferidas críticas à Contabilidade tradicional, em relação ao atendimento das necessidades de informações para investidores, especificamente quanto ao valor patrimonial das empresas. Em virtude de tais críticas, conforme atestam diversas pesquisas relacionadas com avaliação de ativos (tangíveis ou não), os pesquisadores e profissionais da área contábil têm buscado metodologias e modelos que possam acrescentar ao papel informativo da contabilidade, tentando adequá-la às necessidades informativas dos usuários.

Para prover seus usuários com informes estratégicos, a Contabilidade faz uso do processo de identificar, avaliar e registrar as mutações que acontecem no patrimônio das companhias, de modo a fundamentar decisões corretas. Porém, diversos 
fatores que influenciam os componentes patrimoniais são de difícil (ou quase impossível) avaliação, dada a sua natureza intangível. Neste campo enquadramse os Ativos Intangíveis como as políticas de recursos humanos e seus efeitos sobre a produtividade industrial, a participação mercadológica da empresa, o valor das marcas, os impactos ambientais, a imagem da empresa etc.

Esta situação se torna mais problemática na chamada "Nova Economia" ou na "Economia do Conhecimento", na qual o valor é criado por bens intangíveis (como idéias, marcas, know-how, franquias etc) e os sistemas contábeis tradicionais não conseguem captar esta realidade de forma adequada.

Corroborando tal afirmação, Kaplan e Norton (2000, p.12) aduzem que

na economia industrial, as empresas criavam valor a partir de ativos tangíveis, mediante a transformação de matérias-primas em produtos acabados. Um estudo do Brookings Institute, de 1982, mostrou que o valor contábil dos ativos tangíveis representava $62 \%$ do valor de mercado das organizações industriais. Dez anos mais tarde, o índice caiu para $38 \%$. E estudos recentes estimaram que, em fins do século $X X$, o valor contábil dos ativos tangíveis correspondiam a apenas 10 a $15 \%$ do valor de mercado das empresas. Sem dúvida, as oportunidades para a criação de valor estão migrando da gestão de ativos tangíveis para a gestão de estratégias baseadas no conhecimento, que exploram os ativos intangíveis da organização: relacionamentos com os clientes, produtos e serviços inovadores, tecnologia da informação e banco de dados, além de capacidades, habilidades e motivação dos empregados.

Por seu turno, Stewart (2002, p.380) advoga que "[...] os ativos e atividades mais importantes hoje o capital intelectual e o trabalho do conhecimento não são avaliados nem demonstrados de forma adequada." Ressalta, ainda, que o seguimento dos Princípios Contábeis conduz à contabilização inadequada dos principais recursos e atividades das empresas do conhecimento.

Endossando as críticas à Contabilidade, Lev (apud WEBBER, 2000) considera que enquanto os
Ativos Intangíveis vêm gradativamente superando em importância os ativos físicos, os sistemas de avaliação e as demonstrações contábeis não têm refletido adequadamente tal alteração.

A causa do crescimento da atenção dada aos intangíveis, segundo Lev (2001), pode ser atribuída à combinação de dois fatores correlatos: (a) o aumento da concorrência oriundo da globalização e o processo de desregulamentação em áreas vitais da economia, como as telecomunicações e o setor elétrico e (b) o surgimento de novas ferramentas tecnológicas (por exemplo: a Internet e o comércio eletrônico). O referido autor comenta, ainda, que estes dois desenvolvimentos fundamentais - o primeiro no campo econômico/político e o outro no campo tecnológico - acarretaram modificações estruturais nas organizações, acentuando o significado dos Ativos Intangíveis como agregadores de valor à empresa no ambiente mercadológico vigente.

Em função destes fatores, a atenção dos profissionais contábeis tem se voltado para os Ativos Intangíveis. Antunes (2000), referindo-se aos Ativos Intangíveis, assevera que as discussões que o assunto têm provocado nos setores acadêmicos e empresariais ao longo de décadas, em que pese o fato de não haver ainda um consenso, ganham relevância maior com o espaço crescente que os Ativos Intangíveis vêm conquistando na denominada "Nova Economia".

Isso acontece porque a contribuição dos Ativos Intangíveis para o valor econômico das empresas é atualmente bastante clara. ludícibus (1988, p.7-9) chega a atribuir "mais importância ao intangível de um balanço, como elemento de discernimento no que se refere à potencialidade da entidade, do que, às vezes, aos elementos tangíveis."

No entanto, Oliveira (1999) registra que, mesmo considerando a importância assumida pelos Ativos Intangíveis, há uma carência de ferramentas para avaliação dos mesmos. Com isso, os administradores não contam com instrumentos que os auxiliem no esclarecimento de questões importantes, bem como lhes é dificultada a decisão quanto aos investimentos a serem realizados.

Pelo exposto, percebe-se que tais componentes intangíveis adquirem, em face da célere evolução pela qual a administração vem passando, cada vez mais relevância. Isto ocasiona uma necessidade 
crescente de formas de identificação e avaliação destes itens intangíveis. Nessa direção, discorrese na seqüência acerca de estudo de caso que utilizou um modelo objetivando identificar os potenciais geradores de ativos intangíveis numa empresa industrial.

\section{O MODELO UTILIZADO}

O modelo empregado neste estudo de caso foi o "Mapa para Identificação de Potenciais Geradores de Intangíveis", proposto por Wernke (2002). Esse modelo de identificação de Ativos Intangíveis não segue os procedimentos contábeis regulamentados legalmente, sendo uma ferramenta de cunho exclusivamente gerencial para uso interno e externo, conforme a conveniência da divulgação a ser determinada pela empresa que o adotar. Com isso, se exime de seguir critérios contábeis geralmente aceitos, priorizando aspectos notadamente de cunho gerencial que talvez não estejam totalmente de acordo com a prática contábil vigente na atualidade.

Tal modelo fundamenta-se, basicamente, nas três fases que compõem a ferramenta The Value Chain Scoreboard $\circledast$, proposto por Lev (2001) e nas quatro perspectivas do Balanced Scorecard (BSC), de Kaplan \& Norton (2000).

Como as perspectivas "Clientes", "Aprendizado \& Crescimento" e "Processos Internos" do BSC podem ser englobadas ou equivalerem às fases "Comercialização", "Descobertas \& Aprendizagem" e "Implementação" do Scoreboard respectivamente, tal modelo adotou a estrutura básica do modelo de Lev (considerado mais adequado que o BSC para a avaliação de intangíveis) com algumas alterações, adicionando-se a perspectiva "Financeira" num enfoque distinto daquele que originalmente tem sido imputado a esse grupo de indicadores no Balanced Scorecard. O Quadro 1 exibe o modelo em lume.

\begin{tabular}{|c|c|}
\hline \multicolumn{2}{|c|}{ MAPA PARA IDENTIFICAÇÃO DE POTENCIAIS GERADORES DE INTANGÍVEIS } \\
\hline PERSPECTIVAS & GRUPOS DE INDICADORES \\
\hline FINANCEIRA & $\begin{array}{l}\text { GASTOS [associados a fatores] INTANGÍVEIS } \\
\text { Gastos Ambientais } \\
\text { Gastos da Qualidade - Falhas Externas } \\
\text { Gastos com Pesquisa \& Desenvolvimento } \\
\text { Gastos de Desenvolvimento de Software } \\
\text { Gastos de Aquisição de Clientes } \\
\text { Gastos relacionados às Marcas } \\
\text { Gastos de (Re) Organização } \\
\text { AMORTIZAÇÃO DE INTANGívEIS } \\
\text { Vida útil estimada (em anos) dos Intangíveis identificáveis } \\
\text { DESEMPENHO FINANCEIRO } \\
\text { ROI (Return on Investments) } \\
\text { EVA (Economic Value Added) } \\
\text { MVA (Market Value Added) } \\
\text { Lucro Operacional }\end{array}$ \\
\hline
\end{tabular}




\begin{tabular}{|c|c|}
\hline \multicolumn{2}{|c|}{ MAPA PARA IDENTIFICAÇÃO DE POTENCIAIS GERADORES DE INTANGÍVEIS } \\
\hline PERSPECTIVAS & GRUPOS DE INDICADORES \\
\hline $\begin{array}{l}\text { IMPLEMENTAÇÃO\& } \\
\text { PROCESSOS INTERNOS }\end{array}$ & $\begin{array}{l}\text { PROPRIEDADE INTELECTUAL } \\
\text { Patentes, Marcas Registradas, Direitos Autorais } \\
\text { Renovação de Licenças } \\
\text { Royalties de Patentes e Know-how } \\
\text { VIABILIDADETECNOLÓGICA } \\
\text { Testes Clínicos } \\
\text { Aprovação por Órgãos de Controle } \\
\text { Testes Finais ou "Beta Testes" } \\
\text { Visitantes (para home-pages) } \\
\text { CLIENTES } \\
\text { Alianças de Mercado } \\
\text { Suportes à Marca } \\
\text { Mensuração de Freqüência e Lealdade (para home-pages) } \\
\text { FUNCIONÁRIOS } \\
\text { Práticas de trabalho compartillhadas } \\
\text { Retenção } \\
\text { Perícia (conhecimento dos trabalhadores) }\end{array}$ \\
\hline COMERCIALIZAÇÃO & $\begin{array}{l}\text { VENDAS OU TOP LINE } \\
\text { Receitas de Inovações } \\
\text { Crescimento da Fatia de Mercado } \\
\text { Receitas On-line } \\
\text { Receitas de Alianças } \\
\text { Crescimento de Receitas por Segmento } \\
\text { LUCRATIVIDADE } \\
\text { Ganhos de Produtividade } \\
\text { Canais de Suprimento On-line } \\
\text { OPÇÕES DE CRESCIMENTO } \\
\text { Canais de distribuição } \\
\text { Impactos Esperados de Reestruturação } \\
\text { Crescimento Potencial de Mercado } \\
\text { Custo de Capital Esperado } \\
\text { Ponto de Equilíbrio Esperado }\end{array}$ \\
\hline
\end{tabular}

Fonte: Wernke (2002)

\section{Quadro 1 - Mapa para Identificação de Potenciais Geradores de Intangíveis}

Referido modelo pode ser melhor compreendido adotadas, o enfoque defendido para cada perspectiatravés da visualização da figura 1, em que são men- va, as etapas a serem seguidas para a implementação cionadas, de forma resumida, as perspectivas e os procedimentos necessários para cada etapa.

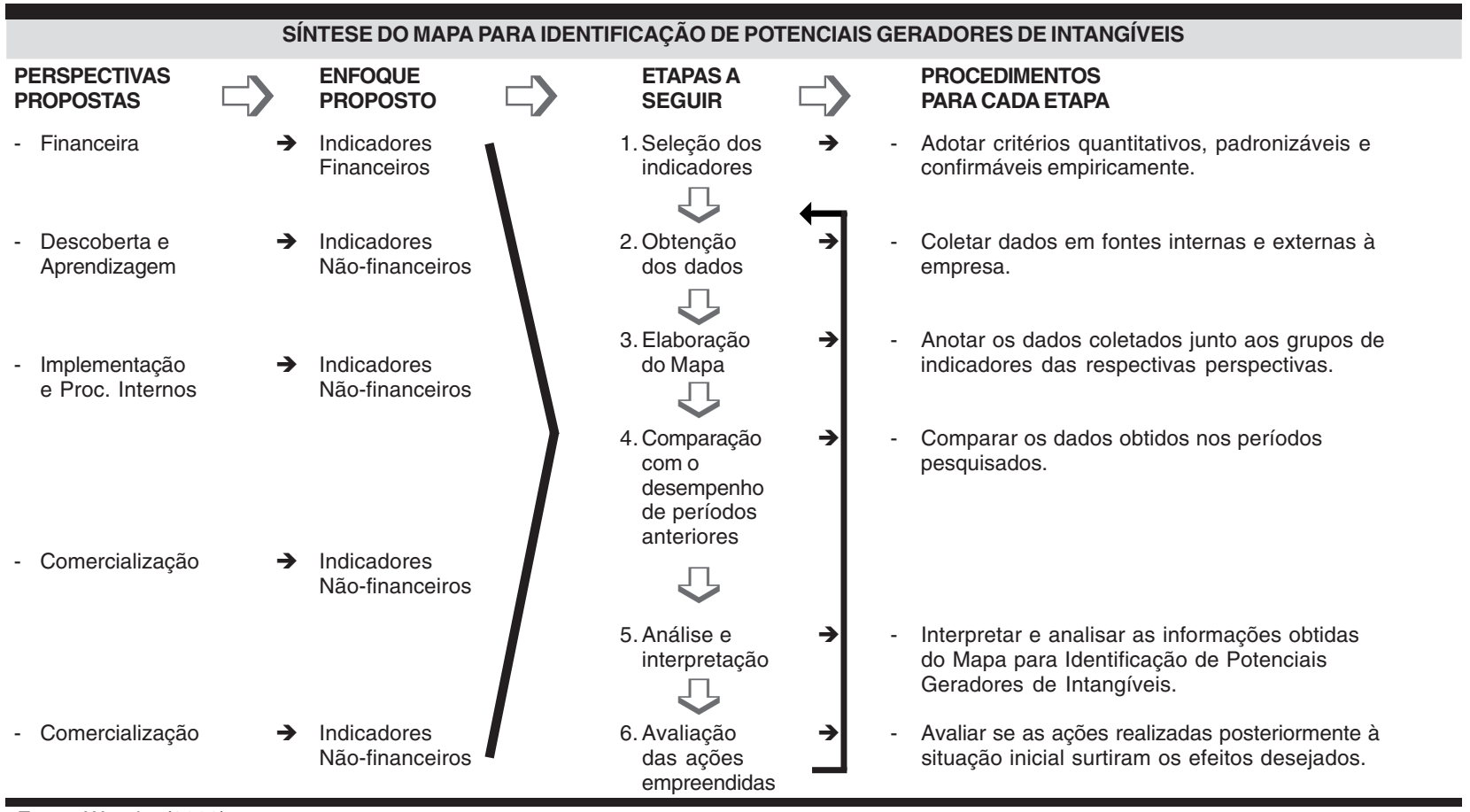

Fonte: Wernke (2002)

Figura 1 - Síntese do modelo utilizado 


\section{APLICAÇÃO DO MODELO}

Neste tópico, é apresentado o estudo de caso relativo à aplicação do Mapa para Identificação de Potenciais Geradores de Intangíveis numa empresa industrial. Com tal finalidade, inicialmente faz-se uma descrição sucinta da empresa e das condições nas quais foi implementado. Em seguida, descreve-se a forma como foi concretizada a aplicação prática, a seqüência das etapas da implementação do modelo desenvolvido e os resultados alcançados. Ainda, procede-se a uma análise dos resultados obtidos, discorre-se sobre as dificuldades encontradas e finaliza-se com a apresentação de uma avaliação global do modelo, de sua aplicação e dos resultados mais relevantes.

\subsection{Descrição da Empresa Pesquisada}

A aplicação prática foi efetuada na empresa "Beta" (nome fictício) que atua principalmente na industrialização e comercialização de máquinas industriais utilizadas em diversos segmentos e tipos de aplicações (fábricas de móveis, molduras, serrarias etc). Situada no sul de Santa Catarina (Brasil), tal entidade é constituída sob a forma de sociedade por quotas de responsabilidade limitada, podendo ser classificada como empresa de pequeno porte se consideradas as características do setor em que atua. As seções vindouras relatam os principais aspectos da aplicação do modelo para identificar potenciais geradores de intangíveis.

\subsection{Implementação do Modelo}

Quando da elaboração do Mapa para Identificação de Potenciais Geradores de Intangíveis na empresa pesquisada foram seguidos determinados procedimentos. As etapas seguidas, os resultados alcançados e as dificuldades surgidas por ocasião da implementação do modelo são relatadas a seguir.

\subsubsection{Seleção dos Indicadores}

Inicialmente foram determinados os indicadores que formaram os grupos componentes de cada perspectiva. Nessa seleção foram consideradas as possibilidades de obtenção de dados de forma contínua, ao longo do tempo, na base de dados disponíveis na empresa (controles internos e software ERP da MicroSiga $\left.{ }^{\circledR}\right)$. Na escolha, foram priorizados indicadores quantitativos, padronizáveis e confirmáveis de forma empírica, que proporcionam comparabilidade entre períodos. Convém ressaltar que os indicadores adotados não abrangem todos os fatores intangíveis relacionados com a empresa pesquisada. Porém, são os considerados de maior importância para a empresa.

Após selecionar os indicadores efetuou-se a coleta dos dados, conforme a seção seguinte.

\subsubsection{Obtenção dos Dados}

Os dados requeridos para municiar os indicadores escolhidos são provenientes de setores distintos como Projetos, Vendas, Produção, Administração, Contabilidade e suas respectivas subdivisões.

No setor de Projetos foram coletados dados relacionados às pesquisas desenvolvidas e em desenvolvimento, equipamentos e softwares utilizados, pessoal envolvido e respectiva qualificação etc. $O$ setor de Vendas informou quanto aos produtos comercializados, às feiras participadas, à situação da clientela, à distribuição de produtos por região etc. O setor de Produção contribuiu com dados e informações relacionadas ao processo industrial e aos funcionários desse departamento.

$\mathrm{Na}$ Contabilidade da empresa foram obtidos dados referentes à parte financeira, como os gastos efetuados nos diversos setores (folha de pagamento, despesas de expediente, investimentos efetuados etc) e os valores necessários aos cálculos dos indicadores de desempenho financeiro (ROI, ROA, ROE, EVA, Lucro Operacional e Faturamento). Os demais dados, excetuados os coletados nos setores mencionados, foram coligidos junto à Administração.

Selecionados os indicadores e coligidos os dados necessários, passou-se a elaborar o Mapa para Identificação de Potenciais Geradores de Intangíveis, como mencionado na próxima seção.

\subsubsection{Elaboração do Mapa para Identificação de Potenciais Geradores de Intangíveis da Empresa "Beta"}

Nas etapas seguidas para a construção do mapa para identificar os potenciais geradores de 
intangíveis da empresa pesquisada foram observados diversos pontos merecedores de destaque nas quatro perspectivas empregadas e nos respectivos indicadores escolhidos, conforme comentado nas próximas seções.

É pertinente enfatizar que, em termos de período abrangido, o trabalho de pesquisa envolveu os meses de julho de 2000 a junho de 2001, consolidados em dois períodos: $2^{\circ}$ semestre de 2000 e $1^{\circ}$ semestre de 2001 . Alguns indicadores, entretanto, não tiveram a necessidade de serem divididos nesses dois períodos porque existiam anteriormente ao período de pesquisa e/ou foram mantidos nos dois semestres analisados sem alterações.

\subsubsection{Perspectiva Financeira}

Para essa perspectiva foram utilizados diversos indicadores nos três grupos propostos pelo modelo, conforme abaixo. No grupo "Gastos [associados a fatores] Intangíveis" foram escolhidos seis indicadores, representados sinteticamente no Quadro 2. Dos indicadores constantes do modelo (vide Quadro 1), apenas os indicadores "Gastos Ambientais" e "Gastos de (Re)Organização" não foram utilizados, tendo em vista que a empresa não desembolsou recursos com atividades enquadráveis nesses itens no período de pesquisa.

\begin{tabular}{|c|c|c|}
\hline INDICADORES ADOTADOS & $2^{\circ}$ Sem./2000 & $1^{\circ} \mathrm{Sem} . / 2001$ \\
\hline 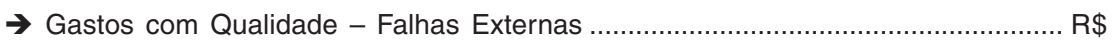 & $8.111,18$ & $4.547,88$ \\
\hline$\rightarrow$ Gastos com Pesquisa e Desenvolvimento de Produtos …................................. $\mathrm{R}$ & $32.110,84$ & $24.987,31$ \\
\hline$\rightarrow$ Gastos com Desenvolvimento/Manutenção de Softwares …............................. $\mathrm{R} \$$ & $7.063,76$ & $9.043,45$ \\
\hline$\rightarrow$ Gastos com Aquisição de tecnologia & $25.000,00$ & $133.000,00$ \\
\hline 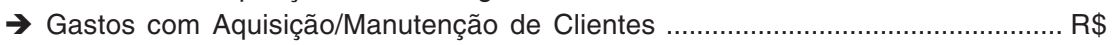 & $49.710,54$ & $50.480,38$ \\
\hline 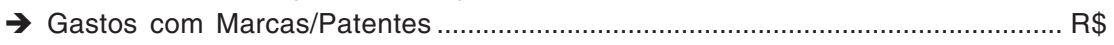 & 320,00 & - \\
\hline$\rightarrow$ Gastos com Desenvolvimento/Capacitação de Pessoal ..................................... $\mathrm{R} \$$ & $18.566,19$ & $24.046,59$ \\
\hline \ TOTAIS & $122.316,32$ & $246.105,61$ \\
\hline
\end{tabular}

Fonte: Wernke (2002)

\section{Quadro 2 - Indicadores do grupo Gastos [associados a fatores] Intangíveis}

Convém frisar que o valor consignado no indicador "Gastos com Marcas/patentes" refere-se somente à atualização cadastral junto ao INPI (Instituto Nacional de Propriedade Industrial), não tendo sido registrados outros desembolsos no período de estudo.

Quanto ao grupo "Amortização de Ativos Intangíveis" não foi possível listar fatores intangíveis com vida útil estimada, como poderiam ser as patentes das máquinas desenvolvidas e comercializadas pela empresa pesquisada. Ressalte-se que, mesmo tendo iniciado o processo de patenteamento de alguns produtos, a empresa ainda não possuía patente aprovada por órgão de registro. Indagado acerca da aparente contradição, o responsável pela área de projetos alegou que, em função do tempo necessário para registro de uma patente de máquina e principalmente pela burocracia e custos envolvidos no processo, a empresa preferia lançar os produtos no mercado sem o respectivo registro. Dessa forma, visa a um retorno mais breve do investimento realizado no projeto.

Em termos de indicadores que integram o grupo "Desempenho Financeiro" foram escolhidos: ROI (Return On Investments), ROA (Return on Assets), ROE (Return on Equity), EVA (Economic Value Added), Lucro Operacional e Evolução do Faturamento. Tais indicadores estão representados na Tabela 1, a seguir.

Tabela 1 - Desempenho financeiro

\begin{tabular}{|c|c|c|}
\hline INDICADORES & $2^{\circ} \mathrm{Sem} / 2000$ & $1^{\circ} \mathrm{Sem} / 2001$ \\
\hline ROI & $16,72 \%$ & $4,34 \%$ \\
\hline ROA $\ldots \ldots \ldots . . . .$. & $15,45 \%$ & $3,67 \%$ \\
\hline$\ldots \ldots \ldots \ldots \ldots \ldots \ldots \ldots \ldots$ & $18,83 \%$ & $3,64 \%$ \\
\hline EVA & $10.261,23$ & $(176.707,84)$ \\
\hline 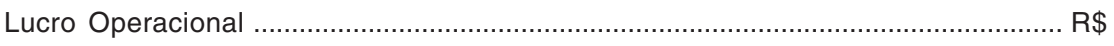 & $256.137,82$ & $67.749,40$ \\
\hline 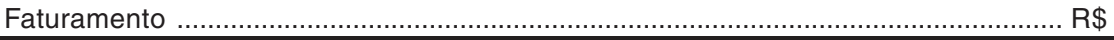 & $1.760 .173,00$ & $1.705 .859,00$ \\
\hline
\end{tabular}

Fonte: Wernke (2002) 
A seção seguinte enfoca a aplicação da perspectiva "Descobertas e Aprendizagem".

\subsubsection{Perspectiva Descobertas e Aprendizagem}

Em relação à perspectiva "Descobertas e Aprendizagem", no agrupamento "Renovação Interna" puderam ser identificadas intangibilidades associadas aos indicadores apresentados resumidamente no Quadro 3.

\section{Pesquisa e desenvolvimento de produtos \\ - Projetos concluídos \\ - Projetos em andamento \\ Desenvolvimento de tecnologia da informação \\ a) Customização do ERP Siga Advanced \\ b) Treinamento/Capacitação de funcionários \\ Política de incentivo à educação \\ Cursos técnicos participados \\ Intranet \\ Disponibilizada para diversos setores \\ Aquisição/Manutenção de clientes \\ Situação dos clientes (ativos/inativos/efetivos) \\ Percentual de vendas por região \\ Fonte: Wernke (2002) \\ Quadro 3 - Resumo dos indicadores do grupo "Renovação Interna"}

No grupo "Conhecimento Adquirido", foram empregados indicadores que demonstram a tecnologia adquirida e empregada em diversos setores no período estudado. Através do indicador "Tecnologia industrial adquirida" verificou-se que foram comprados equipamentos/máquinas industriais em maior quantidade no $1^{\circ} \mathrm{Sem} . / 2001$. No período inicial pesquisado $\left(2^{\circ} \mathrm{Sem} . / 2000\right)$ foi adquirido somente um "Sistema de Pintura Eletrostática com estufa de secagem", enquanto que no $1^{\circ} \mathrm{Sem} . / 2001$ foram compradas: (i) Medidora tridimensional/ software (utilizada no controle de qualidade); (ii) Rebarbadora de peças (usada no processo de tamboreamento); (iii) Mesa de pintura por cortina (utilizada na pintura de fundos) e (iv) Prensa p/ estampagem de 30 toneladas.

Ainda no grupo "Conhecimento Adquirido", foi utilizado o indicador "Tecnologia da informação adquirida (Softwares)". Tal parâmetro revelou os softwares empregados especificamente nos setores de Projetos, Produção e Administrativo, bem como os softwares de uso comum dos setores.
No grupo "Rede de Relacionamentos", foram empregados dois indicadores. O indicador "Alianças para Pesquisa e Desenvolvimento" evidencia que a empresa fez parceria somente com um fornecedor no período abrangido pela pesquisa. Quanto ao indicador "Integração cliente/fornecedor", esse revelou que a empresa manteve contrato de compra com apenas dois fornecedores.

Não foram detectados pontos enquadráveis em "Joint Ventures", conforme proposto no formato original do modelo.

A próxima seção discorre sobre a perspectiva "Implementação e Processos Internos".

\subsubsection{Perspectiva Implementação e Processos Internos}

No que tange à perspectiva "Implementação e Processos Internos", no grupo de indicadores denominado "Propriedade Intelectual", foram elencados itens intangíveis relacionados com "Patentes" e "Marcas Registradas". Conforme já enfatizado na Perspectiva Financeira, a empresa não possui patentes registradas em seu nome. Porém, verificou-se que existem quatro "Pedidos de privilégio" aguardando exame/parecer técnico. Quanto ao quesito "Marcas", a empresa tem registrada a marca mista "INMES" e está com processo de registro da marca nominativa "Rigipontas", cujos gastos respectivos foram efetuados em período anterior ao estudado.

Em "Viabilidade Tecnológica" foram identificados somente fatores relacionados aos indicadores "Aprovação por controles de qualidade internos". Os controles internos listados denotam a preocupação da empresa com a qualidade, visto que adota métodos estatísticos, eletrônicos e visuais na tentativa de assegurar a fabricação de produtos sem defeitos.

Os demais indicadores do modelo utilizado não puderam ser considerados em função das peculiaridades da empresa em estudo.

No grupo "Clientes", foram consignados elementos classificáveis no indicador "Suportes à marca/ produtos". Observou-se que, em relação à "Assistência Técnica", a empresa conta com uma rede de 17 assistentes espalhados pelo país. Foram evidenciados os "Prazos de garantias" concedidos, 
quando se percebeu que, exceto na linha de exaustores, o prazo de garantia concedido é de apenas seis meses. Por último, verificou-se que a empresa adota manuais para uso dos clientes visando a demonstrar as formas de manuseio dos produtos vendidos.

Em "Funcionários", último grupo dessa perspectiva, listaram-se indicadores relacionados às "Práticas de trabalho compartilhadas", "Retenção de funcionários" e "Perícia (grau de conhecimento dos trabalhadores)".

No indicador "Práticas de trabalho compartilhadas" constatou-se que a empresa utiliza (i) manuais para uso interno: que objetivam padronizar procedimentos de fabricação e (ii) programa "Cinco S's": orientando os funcionários quanto à organização do local de trabalho.

Por intermédio do indicador "Retenção de funcionários", verificou-se que, em todo o período abrangido pelo estudo, aconteceram somente duas demissões/admissões, denotando uma estabilidade do corpo funcional da empresa.

No indicador "Perícia (conhecimento dos trabaIhadores)", foram segregados os funcionários quanto ao nível de escolaridade. Apurou-se que apenas 6 funcionários têm instrução "Nível superior completo", o que representa $13,04 \%$. O mesmo percentual se aplica ao número de funcionários com "Segundo grau completo". Cerca de 17,39\% dos funcionários têm "Nível superior incompleto" e $56,52 \%$ dos empregados da empresa não completaram o ensino de segundo grau.

O tópico seguinte versa sobre os principais aspectos da perspectiva "Comercialização".

\subsubsection{Perspectiva Comercialização}

A perspectiva "Comercialização" no mapa de identificação de intangíveis elaborado na empresa "Beta", apresentou indicadores utilizados nos três grupos que o formaram. O grupo "Vendas" foi composto de itens ligados ao indicador de "Participação nas Receitas por Segmentos/Áreas/Linhas", conforme expresso na Tabela 2.
Tabela 2 - Participação nas vendas por linha de produtos

\begin{tabular}{lrr} 
Linha & 2'Sem./2000 & $\mathbf{1}^{\circ}$ Sem./2001 \\
Gramp. INMES & $24,15 \%$ & $16,79 \%$ \\
IM-300 & $7,96 \%$ & 3,10 \\
IM-30 & $12,66 \%$ & $24,29 \%$ \\
Prensa INMES & $0,16 \%$ & $0,17 \%$ \\
Exaustor INMES & $0,85 \%$ & $6,95 \%$ \\
Grampos INMES & $16,59 \%$ & $14,55 \%$ \\
Flexi INMES & $2,01 \%$ & $1,95 \%$ \\
Fundos PR & $5,87 \%$ & $7,87 \%$ \\
Dobradiças & $6,95 \%$ & $5,73 \%$ \\
Suporte INMES & $0,22 \%$ & $0,12 \%$ \\
Gravatas & $0,34 \%$ & $0,49 \%$ \\
Rigipontas & $0,74 \%$ & $1,21 \%$ \\
Aces. Serras & $6,99 \%$ & $5,34 \%$ \\
Aces. Grampeadoras & $1,16 \%$ & $0,65 \%$ \\
Prod. p/Terceiros & $4,95 \%$ & -- \\
Rep. ONMGA & $0,03 \%$ & $0,01 \%$ \\
Romeo Maestri & $1,96 \%$ & $1,05 \%$ \\
Rep. Romeo Maestri & $0,33 \%$ & $0,41 \%$ \\
Ferud & $3,21 \%$ & $5,91 \%$ \\
Ver. Nacional & $1,24 \%$ & $0,64 \%$ \\
Rep. INMES & $1,27 \%$ & $2,54 \%$ \\
Serviços & $0,36 \%$ & $0,23 \%$ \\
\hline
\end{tabular}

Fonte: Wernke (2002)

Em função das limitações informacionais da base de dados disponível não foram utilizados indicadores referentes à "Receitas de Inovações" e "Crescimento de Fatia de Mercado". Com relação a itens enquadráveis nos indicadores "Receitas On-line" e "Receitas de Alianças", sugeridos no modelo original, na empresa pesquisada tais fatores não foram detectados no período de estudo.

No grupo "Lucratividade" somente foram detectados fatores intangíveis ligados a "Ganhos de Produtividade". Para tanto, foram comparados os montantes das receitas (faturamento bruto) de cada período pesquisado em relação ao número de funcionários. Resultou que no $2^{\circ} \mathrm{Sem} . / 2000$ a receita por funcionário foi de $\mathrm{R} \$ 38.264,63(\mathrm{R} \$ 1.760 .173,00$ / 46 empregados), enquanto que no $1^{\circ} \mathrm{Sem} . / 2001$ o resultado foi de $R \$ 37.083,89$ ( $R \$ 1.705 .859,00$ / 46 funcionários).

Os indicadores do grupo "Opções de Crescimento" que foram utilizados dizem respeito a "Canais de Distribuição", não tendo sido identificados outros itens intangíveis enquadráveis nos demais indicadores listados no modelo ora utilizado. A Tabela 3 evidencia a participação das formas de venda. 
Tabela 3 - Vendas por canal de distribuição

\begin{tabular}{lrr}
\hline Forma/Período & $\mathbf{2}^{\circ}$ Sem./2000 & $\mathbf{1}^{\circ}$ Sem./2001 \\
\hline Distribuidores & $60,43 \%$ & $63,20 \%$ \\
Direta & $38,84 \%$ & $35,87 \%$ \\
Representante & $0,73 \%$ & $0,93 \%$ \\
\hline
\end{tabular}

Fonte: Wernke (2002)

Na próxima seção, fazem-se comentários quanto à confrontação do desempenho dos indicadores nos dois períodos estudados.

\subsubsection{Comparação com o Desempenho de Períodos Anteriores}

Como a pesquisa abrangeu dois períodos $\left(2^{\circ} \mathrm{sem} . /\right.$ 2000 e $1^{\circ}$ sem./2001) foi possível realizar uma comparação entre ambos, em termos de desempenho nos diversos indicadores utilizados. Tal confronto proporcionou subsídios para análise e facilitou a interpretação das informações originadas do mapa elaborado.

No que tange à "Perspectiva Financeira", os pontos mais importantes a serem considerados são:

a) quanto ao total de "Gastos [associados a fatores] intangíveis", conforme expresso no Quadro 12, verifica-se um aumento substancial (+ 101,20\%) do primeiro para o segundo período, causado principalmente pela elevação nos "Gastos com Aquisição de Tecnologia";

b) os gastos com falhas internas reduziram-se substancialmente do $2^{\circ} \mathrm{Sem} . / 2000$ para o $1^{\circ} \mathrm{Sem} . / 2001$, apresentando um decréscimo de $43,93 \%$;

c) os valores destinados à pesquisa e desenvolvimento de produtos foram maiores no primeiro semestre pesquisado em virtude da aquisição de equipamentos e material de pesquisa, mantendose o mesmo nível de destinação de recursos quanto aos salários e encargos do setor de projetos;

d) o indicador "Aquisição/Desenvolvimento/Manutenção de softwares" mostra que houve um acréscimo de $28,03 \%$ do primeiro para o segundo período de estudos (de $\mathrm{R} \$ 7.063,76$ para $\mathrm{R} \$$ 9.043,45);

e) em termos de "Aquisição de tecnologia", verificou-se que no $2^{\circ} \mathrm{Sem} . / 2000$ os gastos foram de $\mathrm{R} \$ 25.000,00$ e aumentaram significativamente (+ 432\%) no $1^{\circ} \mathrm{Sem} . / 2001$, quando desembolsaram-se $R \$ 133.000,00$; f) em relação à "Aquisição/Manutenção de clientes", percebeu-se a manutenção do nível de investimentos nesse item, denotando a preocupação da empresa com sua clientela;

g) no período a empresa não teve gastos com "Marcas e Patentes", tendo desembolsado somente $R \$ 320,00$ para alterações de dados cadastrais nos respectivos órgãos de registro.

h) os gastos com "Desenvolvimento/Capacitação de pessoal" passaram de $\mathrm{R} \$ 18.566,19$ no segundo semestre de 2000, para $\mathrm{R} \$ 24.046,59$ no primeiro semestre de 2001 (aumento de $29,52 \%$ ), ocasionado principalmente pelo acréscimo na rubrica "Treinamentos e Cursos (inclui instrução formal)" que quase dobrou de um período para outro $(84,08 \%$ de variação no período pesquisado).

Relativamente ao grupo de indicadores "Amortização de Ativos Intangíveis", em função da empresa não deter registros de patentes ou outros itens enquadráveis nesse indicador, a análise desse tópico ficou prejudicada.

No tocante aos indicadores utilizados em "Desempenho financeiro", constatou-se que o ROI (Return on Investment) passou de 16,72\% no $2^{\circ} \mathrm{Sem} . / 2000$ para 4,34\% no 1'Sem./2001; o ROA (Return on Assets) foi de $15,45 \%$ para $3,67 \%$ no último semestre analisado e o ROE (Return on Equity) que era de $18,83 \%$ no $2^{\circ} \mathrm{Sem} . / 2000$ caiu para $3,64 \%$ no $1^{\circ} \mathrm{Sem} . / 2001$. Por seu turno, o EVA foi positivo ( $\mathrm{R} \$ 10.261,23)$ no $2^{\circ} \mathrm{Sem} . /$ 2000 , mas tornou-se negativo $(\mathrm{R} \$-176.707,84)$ no último semestre estudado. Quanto ao Lucro Operacional, verificou-se que foi de $\mathrm{R} \$ 256.137,82$ no $2^{\circ} \mathrm{Sem} . / 2000$ e passou para $\mathrm{R} \$ 67.749,40$ no $1^{\circ} \mathrm{Sem} . / 2001$. Já o faturamento total conseguido no $1^{\circ} \mathrm{Sem} . / 2001$ foi de $\mathrm{R} \$ 1.705 .859,00$ contra $\mathrm{R} \$ 1.760 .173,00$ do $2{ }^{\circ}$ Sem./2000.

A avaliação da perspectiva "Descobertas e Aprendizagem" pode ser segregada em indicadores de "Renovação interna", "Conhecimento adquirido" e "Rede de relacionamentos". Em relação ao grupo "Renovação interna" foram empregados indicadores relacionados com "Pesquisa e Desenvolvimento de Produtos", "Desenvolvimento de tecnologia da informação", "Treinamento/Capacitação de funcionários", "Intranet" e "Aquisição/Manutenção de clientes".

Verificou-se, no item referente às "Pesquisas e desenvolvimentos de produtos", que no $2^{\circ}$ Sem./2000 
foram concluídos quatro projetos e no $1^{\circ}$ Sem./2001 seis projetos foram finalizados. Em termos de projetos iniciados, em ambos os períodos seis projetos estavam em andamento.

No indicador "Desenvolvimento de tecnologia da informação" constatou-se que a empresa realizou a customização do ERP Siga Advanced, ou seja, no $1^{\circ}$ Sem./2001 foi implementado o módulo Telemarketing; iniciadas as rotinas para gerar informes sobre custos e preços e a preparação para instalação da versão Proteus 5.0 do mesmo ERP (prevista para o $2^{\circ} \mathrm{Sem} . /$ 2001). Convém ressaltar que os demais módulos do Siga foram implementados até o $2^{\circ}$ sem./2000.

$\mathrm{O}$ indicador "Treinamento/Capacitação de funcionários" foi subdividido em dois itens. Na "Política de incentivo à educação", registrou-se a preocupação da empresa em aprimorar o nível de escolaridade dos seus colaboradores ao subsidiar o ensino de $1^{\circ}$ e $2^{\circ}$ graus com $100 \%$ do valor das mensalidades. Da mesma forma, incentiva a participação em cursos de graduação, de treinamento profissional, de idiomas e de computação com percentuais distintos conforme o tempo de trabalho na empresa e o cargo ocupado pelo funcionário. No item "Cursos técnicos participados", consta que a área técnica (industrial) da empresa participou de apenas três cursos durante o $2^{\circ} \mathrm{Sem} . /$ 2000 e nenhum no $1^{\circ} \mathrm{Sem} . / 2001$.

Quanto ao indicador "Intranet", constatou-se que tal ferramenta de comunicação está disponível nos setores de Vendas, Informática, Projetos, Industrial e Administração desde o $1^{\circ} \mathrm{Sem} . / 2001$. Mesmo que muito disseminada em outros ambientes, na empresa constitui-se de algo relativamente recente e ainda não dominada por todos os funcionários, ocasionando sua inclusão nesse grupo de indicadores.

O último indicador de "Renovação interna" versa sobre "Aquisição/Manutenção de clientes". Nesse item, foi averiguada a "Situação dos clientes (no último mês do Semestre)" e o "Percentual de vendas por região" em cada semestre pesquisado, conforme demonstrado na Tabela 4.

Tabela 4 - Aquisição/manutenção de clientes

\begin{tabular}{lrr}
\hline SITUAÇÃO DOS CLIENTES (no último mês do semestre) & $\mathbf{2}^{\circ}$ Sem./2000 & $\mathbf{1}^{\circ}$ Sem./2001 \\
& N $^{\circ}$ clientes & $N^{\circ}$ clientes \\
Ativos & 400 & 447 \\
Inativos & 1.948 & 1.901 \\
Efetivos & 148 & 151 \\
Total & 2.496 & 2.499 \\
PERCENTUAL DE VENDAS POR REGIÃO & $\mathbf{2}^{\circ}$ Sem./2000 & $\mathbf{1}^{\circ}$ Sem./2001 \\
Sul & $49,79 \%$ & $53,20 \%$ \\
Sudeste & $38,96 \%$ & $37,08 \%$ \\
Nordeste & $5,91 \%$ & $6,56 \%$ \\
Norte & $0,42 \%$ & $0,34 \%$ \\
Centro-oeste & $4,92 \%$ & $2,82 \%$ \\
\hline
\end{tabular}

Fonte: Wernke (2002)

Em relação à "Situação dos clientes", constata-se que houve um acréscimo no número de clientes "ativos", passando de 400 para 447 do semestre inicial para o posterior $(+11,75 \%)$. Quanto aos clientes da categoria "Efetivos", o número de enquadramentos teve variação mínima (de 148 para $151)$ entre os dois períodos pesquisados.

No que tange ao "Percentual de vendas por região", foi notória a grande participação das vendas nas regiões Sul e Sudeste no total de vendas da empresa $\left(88,75 \%\right.$ no $2{ }^{\circ}$ Sem. $/ 2000$ e $90,28 \%$ no $\left.1^{\circ} \mathrm{Sem} . / 2001\right)$.
Na perspectiva "Descobertas e Aprendizagem", foi empregado também o grupo de indicadores denominado "Conhecimento Adquirido", no qual foram utilizados os parâmetros "Tecnologia industrial adquirida" e "Tecnologia de informação adquirida (softwares)".

Em termos de "Tecnologia industrial adquirida", constatou-se um aumento substancial de aquisições tecnológicas do primeiro semestre pesquisado para o segundo. Tal assertiva se fundamenta no fato de que no $2^{\circ} \mathrm{Sem} . / 2000$ foi adquirido somente um "Sistema Pintura Eletrostática 
c/estufa de secagem", enquanto, no $1^{\circ}$ Sem./2001, foram adquiridos quatro equipamentos (medidora tridimensional/software, rebarbadora de peças, mesa de pintura por cortina e prensa para estampagem de 30 toneladas).

Por intermédio do indicador "Tecnologia de informação adquirida (softwares)", determinou-se o grau de informatização ou de softwares disponíveis nos diversos setores da empresa. No setor de Projetos, destacam-se os softwares para desenvolvimento de projetos e embalagens (Solid Works, Auto CAD R14 e Corel Draw). No ambiente do setor de Produção, verifica-se um elevado grau de automação, principalmente através do "Directa Automação DNC" (que faz a comunicação entre computadores e máquinas com comando numérico computadorizado - CNC) e do "Aplicativo Geopak - Win MMC (que realiza o controle de processo e medição de peças). No setor Administrativo, registrou-se, além do ERP Siga, diversos outros softwares de uso comum nas atividades administrativas. Além dos softwares específicos para os setores, a empresa utiliza softwares de uso comum dos setores, como os aplicativos da Microsoft (Office, Internet Explorer, Outlook, Intranet) e antivírus Norton.

O último grupo da perspectiva "Descobertas e Aprendizagem" é denominado "Rede de Relacionamentos", que é subdividido em dois indicadores.

No item "Alianças para Pesquisa e Desenvolvimento" consta que, no período de pesquisa, a empresa celebrou somente um acordo com fornecedores (Pacar). Quanto à "Integração cliente/fornecedor", durante a pesquisa a empresa manteve apenas dois contratos de fornecimento (Xalingo e WEG Motores).

A terceira perspectiva do modelo é a "Implementação e Processos Internos" e sua aplicação prática se subdividiu em quatro grupos de indicadores.

Através do grupo "Propriedade intelectual", percebeu-se que a empresa tem quatro "Pedidos de privilégios" de patentes protocolados em período anterior ao pesquisado, ou seja, não detinha registro de patentes, mas possui quatro processos aguardando exames técnicos e deferimento das patentes. Conforme enfatizado alhures, é política da empresa comercializar os produtos que desenvolve mesmo antes de concedido o registro definitivo. Em termos de "Marcas", a empresa possui uma marca mista registrada (INMES) e outra, nominativa, aguardando deferimento do registro (RIGIPONTAS). Ambos os procedimentos foram realizados em período anterior ao abrangido pela pesquisa.

O segundo grupo de indicadores da perspectiva "Implementação e Processos Internos" é denominado "Viabilidade tecnológica". Em face das características da empresa foi empregado somente o indicador "Aprovação por controles de qualidade internos", que se mantiveram os mesmos nos dois semestres pesquisados.

Também no grupo "Clientes" foi utilizado somente um parâmetro. O indicador "Suportes à marca/ produtos" revela que a empresa mantem uma rede de 17 assistentes técnicos espalhados pelo País e que concede prazos de garantia de fabricação de seus produtos de seis meses (exceto para exaustores, cuja garantia é de 24 meses). Ainda, foi constatado que a empresa adota manuais de utilização para todos os produtos e fita de vídeo para utilização dos grampeadores. O confronto desses indicadores, nos dois semestres da pesquisa, indica que tiveram comportamento semelhante no período.

O quarto e último grupo dessa perspectiva lista indicadores relacionados com o grupo "Funcionários".

No indicador "Práticas de trabalho compartilhadas", constata-se que a empresa adotou, durante todo período de pesquisa, diversos manuais para uso interno que normatizam procedimentos relacionados aos processos de fabricação, projeto, inspeção de qualidade, assistência técnica e requisição/utilização de materiais.

Ainda em "Práticas de trabalho compartilhadas" encontra-se que a empresa implementou, desde 1999, um programa 5S's em todos os setores e o manteve posteriormente. O indicador "Retenção de funcionários" mostra que, no período de pesquisa, aconteceram somente duas demissões/admissões, evidenciando estabilidade no quadro funcional.

$\mathrm{O}$ último indicador utilizado diz respeito à "Perícia (conhecimento dos trabalhadores)". Destacam-se o alto percentual de funcionários sem o segundo grau completo $(56,52 \%)$ e o pequeno percentual de colaboradores com instrução de nível superior $(13,04 \%)$. 
A quarta perspectiva do modelo é a "Comercialização". Na aplicação prática do modelo, tal perspectiva foi composta por três grupos de indicadores: Vendas, Lucratividade e Opções de crescimento.
Em "Vendas" apurou-se a "Participação nas receitas por linhas de produtos", mostrando que os percentuais de cada linha tiveram variação entre os dois semestres pesquisados, conforme expresso na Tabela 5.

Tabela 5 - Variação da participação na receita total, por linha de produtos

\begin{tabular}{|c|c|c|c|}
\hline Linhas & $\begin{array}{c}(A) \\
2^{\circ} \text { Sem./2000 }\end{array}$ & $\begin{array}{c}(B) \\
1^{\circ} \text { Sem./2001 }\end{array}$ & $\begin{array}{c}\text { Variação }(A \rightarrow B) \\
\text { (em relação ao total) }\end{array}$ \\
\hline Gramp. INMES & $24,15 \%$ & $16,79 \%$ & $-7,36 \%$ \\
\hline IM-300 & $7,96 \%$ & $3,10 \%$ & $-4,86 \%$ \\
\hline IM-30 & $12,66 \%$ & $24,29 \%$ & $+11,63 \%$ \\
\hline Prensa INMES & $0,16 \%$ & $0,17 \%$ & $+0,01 \%$ \\
\hline Exaustor INMES & $0,85 \%$ & $6,95 \%$ & $+6,10 \%$ \\
\hline Grampos INMES & $16,59 \%$ & $14,55 \%$ & $-2,04 \%$ \\
\hline Flexi INMES & $2,01 \%$ & $1,95 \%$ & $-0,06 \%$ \\
\hline Fundos PR & $5,87 \%$ & $7,87 \%$ & $+2,00 \%$ \\
\hline Dobradiças & $6,95 \%$ & $5,73 \%$ & $-1,22 \%$ \\
\hline Suporte INMES & $0,22 \%$ & $0,12 \%$ & $-0,10 \%$ \\
\hline Gravatas & $0,34 \%$ & $0,49 \%$ & $+0,15 \%$ \\
\hline Rigipontas & $0,74 \%$ & $1,21 \%$ & $+0,47 \%$ \\
\hline Aces. Serras & $6,99 \%$ & $5,34 \%$ & $-1,65 \%$ \\
\hline Aces. Grampeadoras & $1,16 \%$ & $0,65 \%$ & $-0,51 \%$ \\
\hline Prod. p/Terceiros & $4,95 \%$ & - & $-4,95 \%$ \\
\hline Rep. ONMGA & $0,03 \%$ & $0,01 \%$ & $-0,02 \%$ \\
\hline Romeo Maestri & $1,96 \%$ & $1,05 \%$ & $-0,91 \%$ \\
\hline Rep. Romeo Maestri & $0,33 \%$ & $0,41 \%$ & $+0,08 \%$ \\
\hline Ferud & $3,21 \%$ & $5,91 \%$ & $+2,70 \%$ \\
\hline Ver. Nacional & $1,24 \%$ & $0,64 \%$ & $-0,60 \%$ \\
\hline Rep. INMES & $1,27 \%$ & $2,54 \%$ & $+1,27 \%$ \\
\hline Serviços & $0,36 \%$ & $0,23 \%$ & $-0,13 \%$ \\
\hline
\end{tabular}

Fonte: Wernke (2002)

No grupo de indicadores do modelo chamado de "Lucratividade" foi utilizado na aplicação prática somente o indicador "Ganhos de produtividade". Nesse indicador constatou-se que a evolução foi de -3,09\% (três vírgula zero nove porcento negativos).

No grupo "Opções de crescimento" foi utilizado apenas o indicador "Canais de distribuição". Conforme evidenciado no Quadro 15, os percentuais verificados, nos dois períodos analisados, divergiram minimamente.

\subsubsection{Análise e Interpretação das Informações Obtidas}

Dentre as informações obtidas com a elaboração do Mapa para Identificação de Potenciais Geradores de Intangíveis da empresa "Beta" cabe que sejam analisadas e interpretadas as mais relevantes de cada perspectiva adotada, conforme a seguir.
Em relação à "Perspectiva Financeira", no grupo de indicadores "Gastos [associados a fatores] intangíveis" o aumento de $101,20 \%$ no total desembolsado foi causado principalmente pela elevação nos "Gastos com Aquisição de Tecnologia" que passou de $\mathrm{R} \$ 25.000,00$ no $2^{\circ}$ Sem./2000 para $\mathrm{R} \$ 133.000,00$ no $1^{\circ} \mathrm{Sem} . / 2001$, demonstrando a clara intenção de manter atualizados ou aprimorar os equipamentos industriais usados pela empresa.

A redução constatada no $1^{\circ}$ sem./2001 nos gastos com assistência técnica, evidenciada no indicador "Qualidade (Falhas Externas)", pode ser associada à aquisição de medidora tridimensional empregada no controle de qualidade e adquirida nesse semestre.

A empresa manteve os mesmos gastos com pessoal ligado à "Pesquisa e desenvolvimento de produtos" nos dois semestres. Entretanto, o valor investido em equipamentos e material de pesquisa foi menor no $1^{\circ} \mathrm{Sem} . / 2001$. Como tais equipamentos/materiais 
têm vida útil longa, a diminuição de aquisições, no segundo período pesquisado, não chega a ser um fator preocupante.

O aumento de $28,03 \%$ do primeiro período estudado para o segundo, verificado no indicador "Aquisição/Desenvolvimento/Manutenção de Softwares”, denota uma preocupação dos administradores em aprimorar as ferramentas de informática utilizadas no cotidiano da empresa.

No que respeita ao indicador "Aquisição/Manutenção de Clientes", os gastos enquadráveis nessa medida tiveram valores semelhantes nos dois períodos abrangidos pelo estudo. Vale destacar o aumento do valor despendido com participações em feiras $(35,96 \%)$ no $1^{\circ} \mathrm{Sem} .2001$, compensado pela redução de valores relacionados com "Outros gastos com clientes". A participação em feiras, segundo informações do departamento comercial, tem sido a forma mais eficiente de divulgação de produtos no segmento e, por isso, a empresa passou a enfatizar mais esse tipo de evento.

Durante o período de pesquisa, a empresa não registrou gastos pertinentes a registros de marcas ou patentes. Considerando-se que a atividade principal da empresa é a fabricação de máquinas e equipamentos industriais, tal fato pode ser caracterizado como preocupante, mesmo levando-se em conta a política de registro de patentes da empresa comentada anteriormente.

Um acentuado aumento observado no indicador "Desenvolvimento/Capacitação de pessoal" teve como causa principal o maior valor investido em "Treinamentos e Cursos". Esse ponto evidencia a preocupação da empresa em aprimorar seu quadro de pessoal, principalmente pela constatação de que menos de $15 \%$ dos funcionários têm escolaridade de nível superior (vide o indicador "Perícia (conhecimento dos trabalhadores)", da perspectiva Implementação e Processo Internos).

No que se refere aos indicadores utilizados no grupo "Desempenho financeiro", esses demonstraram que houve queda significativa em ambos na comparação entre o $2^{\circ} \mathrm{Sem} . / 2000$ e o $1^{\circ} \mathrm{Sem} . / 2001$. O ROI teve variação negativa de $74,04 \%$ (de $16,72 \%$ para $4,34 \%$ ), enquanto o ROA decresceu em $76,25 \%$ (de $15,45 \%$ para $3,67 \%$ ) e o ROE reduziu-se em $80,67 \%$ (de $18,83 \%$ caiu para $3,64 \%$ ). Quanto ao EVA (que foi positivo no $2^{\circ} \mathrm{Sem} . / 2000$ e negativo no $1^{\circ} \mathrm{Sem} . / 2001$ ), tal indicador significa que no $2^{\circ} \mathrm{Sem} . / 2000$ o lucro obtido foi suficiente para superar o custo do capital próprio empregado e ainda gerar riqueza para os acionistas. Ao contrário do $1^{\circ} \mathrm{Sem} . / 2001$, em que o lucro gerado pelas atividades da empresa não foi suficiente para proporcionar um EVA positivo, ocasionando a "destruição" da riqueza dos investidores nesse semestre. Tal queda no desempenho financeiro está relacionada à diminuição do Lucro Operacional que era de $\mathrm{R} \$ 256.137,82$ no $2^{\circ}$ Sem./2000 e passou para $\mathrm{R} \$ 67.749,40$ no $1^{\circ} \mathrm{Sem}$. de 2001 (variação negativa de $73,55 \%$ entre os dois períodos). Contribuiu para a redução do lucro operacional o menor faturamento conseguido no $1^{\circ} \mathrm{Sem} . / 2001$ ( $\mathrm{R} \$ 1.705 .859,00$ contra $\mathrm{R} \$ 1.760 .173,00$ do $2^{\circ}$ Sem./2000).

Pelo lado da perspectiva "Descobertas e Aprendizagem", cabe que sejam destacados alguns pontos. No grupo de indicadores "Renovação interna", constatou-se que o número de projetos concluídos e em andamento nos dois semestre analisados foram semelhantes (quatro e seis projetos concluídos, respectivamente para o $2^{\circ} \mathrm{sem} . / 2000$ e $1^{\circ} \mathrm{Sem} . / 2001$ e seis projetos em andamento em cada semestre) . Isso permite interpretar que o setor de projetos tem boa produtividade, mantendo média próxima de um projeto concluído e um projeto iniciado por mês, durante todo o período de pesquisa. Ainda, em função do porte da empresa, tais números de projetos concluídos/ iniciados demonstra a prioridade dada pelos gestores à constante inovação de produtos.

No indicador "Desenvolvimento de tecnologia da informação", foram realizados apenas procedimentos quanto à customização do ERP utilizado pela companhia.

A preocupação dos dirigentes da empresa em relação à melhoria do nível de instrução dos funcionários resta evidente no indicador "Treinamento/ Capacitação de funcionários”, principalmente em razão das políticas de incentivo à educação adotadas. Tal atenção se justifica pelo baixo número de funcionários com instrução superior, já comentado. Vale ressaltar que, no $1^{\circ} \mathrm{Sem} . / 2001$, não foi verificada a participação de funcionários em cursos da área técnica, ensejando à administração uma análise mais acurada quanto a esse ponto.

Quanto à "Situação dos clientes", merecem maiores atenções os clientes classificáveis como "Ativos" e "Efetivos". Percebe-se pela análise dos clientes 
"ativos" um aumento de $11,75 \%$ do $2{ }^{\circ}$ Sem./2000 para o $1^{\circ} \mathrm{Sem} . / 2001$. Entretanto, a evolução dos clientes que compram continuadamente (mais de uma vez no período) ou "Efetivos" foi de apenas 2,03\% entre os dois semestres pesquisados. Esse ponto merece maior consideração do departamento comercial na tentativa de determinar as causas desse pequeno percentual de clientes contumazes.

O percentual elevado de vendas nas regiões Sul e Sudeste nos dois semestres pode ser considerado normal em função da proximidade geográfica e principalmente pela economia dessas duas regiões. Por outro lado, o pequeno percentual de vendas nas demais regiões pode indicar a necessidade de iniciativas do departamento de vendas para tais mercados, até mesmo como forma de ampliar a base de clientes (que conforme comentado anteriormente, cresceu pouco nos dois períodos em análise). Além disso, cabe que sejam encetadas medidas para exportar, visto que tal forma de comercialização não foi constatada.

No que se refere ao grupo de indicadores "Conhecimento Adquirido", o indicador "Tecnologia industrial adquirida" demonstra que no $1^{\circ} \mathrm{Sem} . / 2001$ aconteceram mais aquisições que no semestre anterior, evidenciando a intenção da empresa em melhor equipar ou atualizar seus equipamentos industriais.

Pelo indicador "Tecnologia de informação adquirida (softwares)" são conhecidos os aplicativos utilizados nos setores de Projetos, Produção, Administração e os softwares de uso comum dos departamentos. O emprego de tais ferramentas denota um alto grau de informatização dos procedimentos nos diversos setores, contribuindo para melhorar a produtividade e a qualidade do trabalho executado .

No grupo de indicadores denominado "Descobertas e Aprendizagem", verifica-se que a empresa manteve apenas um acordo com fornecedor e apenas dois contratos de fornecimento. Os registros desses dois indicadores sinalizam um ponto que requer uma análise mais criteriosa por parte da empresa em estudo, visto que atualmente as alianças com fornecedores $e$ clientes tendem a ser comuns, notadamente pela preocupação com a cadeia de valores na qual está inserida a organização. Ainda, a inexistência de convênios com universidades ou centros de pesquisa também pode ser considerada como um ponto a ser melhor analisado pelos administradores.

A perspectiva "Implementação e Processo Inter- nos" mostrou, através do grupo de indicadores "Propriedade Intelectual", o atual estágio da empresa quanto à propriedade ou detenção de direitos relacionados a marcas e patentes. Por possuir somente o registro de uma marca e estar aguardando deferimento de registro de outra, bem como não dispor de qualquer patente registrada, pode-se considerar que tal situação é inadequada. A política adotada pela empresa de comercializar seus produtos sem registro pode, a longo prazo, trazer problemas com concorrentes e conseqüências indesejáveis, necessitando ser revista.

Pelo indicador do grupo "Viabilidade Tecnológica" denominado "Aprovação por controles de qualidade internos" é possível atestar a preocupação com a qualidade dos produtos. As diversas formas adotadas para controlar a qualidade dos artigos produzidos indicam que a empresa dá especial atenção a esse quesito, em consonância com as exigências do mercado consumidor mundial. Por outro lado, não existia, no período pesquisado, qualquer iniciativa em termos de obtenção de certificação de qualidade nos moldes das normas I.S.O. 9000 e afins. Isso contradiz, de certa forma, a ênfase dada à qualidade dos equipamentos e máquinas fabricados na empresa pesquisada.

O indicador "Suportes à marca/produtos", que foi o único indicador utilizado no grupo "Clientes", evidenciou que há uma rede de 17 assistentes técnicos no país e que a empresa concede pequenos prazos de garantia à maioria dos produtos comercializados (em geral são seis meses de garantia). Segundo informações da área de projetos, a garantia por esse prazo exíguo é praxe no segmento. Sugere-se, então, mediante estudos técnicos, verificar a possibilidade de ampliar tais prazos como forma de distinguir a empresa dos concorrentes.

No grupo de indicadores "Funcionários", através do parâmetro "Práticas de trabalho compartilhadas", percebeu-se que há a adoção de manuais para uso interno, relacionados com diversos procedimentos ligados a projetos e à produção. Além de padronizar as atividades internas, os manuais têm a propriedade de compartilhar o conhecimento das práticas de trabalho necessárias, evitando o monopólio de informações por determinados funcionários. Ainda, constatou-se que a empresa mantém, desde 1999, um programa 5'S em todos os setores, mesmo não tendo iniciado o processo de certificação, conforme comentado anteriormente. 
Um ponto positivo é salientado através do indicador "Retenção de funcionários". O baixo índice de turnover demonstra que a empresa, a princípio, parece ser um local agradável de trabalhar ou oferece condições de trabalho adequadas aos funcionários. Outro fator que pode ser considerado, nessa análise, é a carência de oportunidades de trabalho em empresas similares na região, que pode contribuir com a pequena rotatividade.

O indicador "Perícia (conhecimento dos trabalhadores)" traz à tona o baixo nível de escolaridade dos funcionários da empresa. Mais da metade dos empregados não concluiram o curso de ensino médio ( $2^{\circ}$ grau) e apenas $13,04 \%$ têm formação universitária. Esse nível de escolaridade enseja que a empresa tente sanar tal deficiência por intermédio da política de incentivo à educação, mencionada na perspectiva "Descobertas e Aprendizagem".

Na perspectiva "Comercialização" foram adotados três grupos de indicadores. No grupo "Vendas", foi possível comparar o desempenho em função da participação de cada linha de produtos nas vendas totais. As principais reduções de participação na receita total ocorreram com as linhas Gramp. INMES, IM300, Grampos INMES e Prod.p/Terceiros. Os mais relevantes aumentos de participação, no total das receitas, aconteceram nas linhas IM-30 (com 11,63\% de acréscimo em relação ao primeiro semestre pesquisado), Exaustor INMES (6,10\%), Fundos PR $(2,00 \%)$ e Ferud $(2,70 \%)$. Convém salientar, entretanto, que, em termos de valor $(\mathrm{R} \$)$, as receitas do $2^{\circ} \mathrm{Sem} . /$ 2000 foram maiores que as auferidas no $1^{\circ}$ Sem./2001.

O indicador "Ganhos de produtividade", pertencente ao grupo "Lucratividade" assinala que houve pequena redução no quociente "Receita por funcionário", mostrando uma diminuição na capacidade de geração de receitas do primeiro para o segundo período de pesquisa.

As variações ocorridas no indicador "Canais de distribuição", do grupo "Opções de crescimento", foram mínimas se comparados os dois semestres estudados. Tais alterações podem ser consideradas apenas como um efeito do comportamento conjuntural do mercado, sem maiores conseqüências à empresa.

No próximo tópico, enfoca-se a avaliação das ações empreendidas no período pesquisado e seus reflexos na empresa.

\subsubsection{Avaliação das Ações Empreendidas}

Após a análise e interpretação das informações obtidas, conforme abordado na seção anterior, foram avaliadas as ações que a empresa empreendeu nos períodos pesquisados. Tal procedimento visa a identificar os reflexos da mudança ou manutenção das políticas da empresa relacionadas com os fatores intangíveis.

Analisados de forma mais abrangente, os indicadores utilizados, no estudo de caso, revelaram algumas situações que puderam ser inferidas como relações de causa e efeito entre os mesmos. Ou seja, alterações em determinados indicadores podem influenciar (ou influenciaram) um ou mais dos outros parâmetros adotados, de forma direta ou indireta. Dentre as possibilidades verificadas, destacam-se as relacionadas com (i) controle de qualidade, (ii) gestão de clientes, (iii) gestão de recursos humanos e (iv) pesquisa e desenvolvimento de produtos.

No âmbito da qualidade percebeu-se que o investimento em uma máquina "medidora tridimensional/ software" contribuiu diretamente para a redução nos gastos com assistência técnica em relação ao período anterior. Tal gasto, registrado na Perspectiva Financeira, implicou na inserção de um item no indicador "Tecnologia industrial adquirida" do grupo "Conhecimento Adquirido" da Perspectiva Descobertas e Aprendizagem. Indiretamente interfere na Perspectiva Implementação e Processos Internos, no indicador "Aprovação por controles de qualidade internos" do grupo de indicadores denominado "Viabilidade tecnológica"; bem como no grupo "Funcionários" (da mesma perspectiva), através do indicador "Práticas de trabalho compartilhadas", tendo em vista que alterou os "Manuais para uso interno" no que diz respeito aos procedimentos para inspeção de qualidade.

No que se refere à gestão da clientela, a manutenção dos mesmos níveis de investimentos nos dois semestres analisados (vide o indicador "Aquisição/ Manutenção de clientes" do grupo "Gastos [associados a fatores] intangíveis" da Perspectiva Financeira), provavelmente implicou que os indicadores relacionados no grupo "Aquisição/Manutenção de clientes do grupo "Renovação Interna" da Perspectiva Descobertas e Aprendizagem também oscilassem minimamente nos dois semestres analisados. Ou seja, os indicadores "Situação dos clientes" e "Percentual 
de vendas por região" tiveram variações pequenas do $1^{\circ}$ para $02^{\circ}$ semestre estudado. Corroborando tal conclusão, constatou-se que, na Perspectiva Comercialização, o indicador "Canais de distribuição" do grupo "Opções de crescimento" teve, também, alterações insignificantes, podendo ambas serem atribuídas a fatores meramente conjunturais do segmento de atuação da empresa. Além disso, um outro ponto que merece ser destacado é que na perspectiva Implementação e Processos Internos, especificamente no indicador "Suporte à marca/produtos" do grupo "Clientes", verificou-se a manutenção das mesmas práticas nos dois períodos enfocados.

Relativamente à gestão de recursos humanos constatou-se que os gastos registrados no indicador "Desenvolvimento/capacitação de pessoal" (do grupo "Gastos [associados a fatores] intangíveis" da Perspectiva Financeira) aumentaram em cerca de $30 \%$ do $1^{\circ}$ para o $2^{\circ}$ semestre pesquisado, com alterações significativas principalmente em "Treinamentos e Cursos (inclui instrução formal)" e "Benefícios indiretos (exceto salários/encargos)". Tais gastos impactam diretamente no indicador "Treinamento/ Capacitação de funcionários" inserido no grupo "Renovação Interna" da Perspectiva Descobertas e Aprendizagem. Esse, por sua vez, pode impactar (ou impactou) no indicador "Retenção de funcionários", no qual se aferiu uma estabilidade no quadro funcional, com baixo turnover. Na mesma direção, os gastos com a política de incentivo à educação implicam em efeitos, mediatos ou não, no indicador "Perícia (conhecimento dos trabalhadores)".

Quanto às associações de causa e efeito relacionadas com pesquisa e desenvolvimento (P\&D) de produtos é possível tecer algumas considerações a respeito. Examinando a Perspectiva Financeira, constatou-se que, nos dois semestres analisados, a empresa teve gastos semelhantes, em termos de valor, com "Salários e Encargos do Setor de Projetos" e reduziu bastante (-57,73\%) os "Gastos com Equipamentos e material de pesquisa" do $1^{\circ}$ para o $2^{\circ}$ semestre estudado. Convém salientar que menos dispêndios com material e equipamentos de pesquisa não implicam, necessariamente, em prejuízo à capacidade de pesquisa do setor em função da vida útil dos materiais adquiridos anteriormente. Assim, a manutenção do montante destinado à remuneração dos funcionários do setor de projetos talvez tenha sido o fator primordial no desempenho também semelhante nos dois semestres no indicador "Pesquisa e Desenvolvimento de produtos", do grupo "Renovação Interna" da Perspectiva Descobertas e Aprendizagem. Em tal indicador percebe-se que, em termos de "Projetos Concluídos", no $2^{\circ}$ Sem./2000 registrou-se a conclusão de quatro projetos, enquanto no $1^{\circ}$ Sem./2001 foram concluídos seis projetos. No tocante a "Projetos em Andamento", detectou-se que havia seis projetos sendo desenvolvidos nos dois semestres pesquisados. Pode ter contribuído para tal desempenho o fato de que o indicador "Alianças para Pesquisa e Desenvolvimento" (Fornecedores) e "Integração Cliente/Fornecedor", ambos do grupo "Rede de Relacionamentos" da Perspectiva Descobertas e Aprendizagem, terem permanecido sem alteração durante todo o período de estudo. Outro ponto que poderia ter ligação estreita com os gastos com P\&D, são os indicadores adotados no Grupo "Propriedade Intelectual" da Perspectiva Implementação e Processos Internos. Todavia, a política de registro de patentes da empresa (já comentada) prejudica tal inferência.

Ressalve-se, por outro lado, que pela peculiaridade do efeito assíncrono, que caracteriza muitos Ativos Intangíveis, nem sempre alterações nos indicadores das perspectivas não-financeiras afetam os parâmetros empregados no grupo "Desempenho Financeiro" da Perspectiva Financeira, de forma direta. Idem no sentido inverso, quando um dispêndio de recursos pode impactar, mediata ou imediatamente, nas demais perspectivas em períodos futuros ou não, dependendo do item a que referir-se.

A seção seguinte mostra as dificuldades encontradas quando da implementação do modelo.

\subsection{Dificuldades Encontradas na Aplicação do Modelo}

Dentre as dificuldades encontradas na aplicação do Mapa para Identificação de Potenciais Geradores de Intangíveis na empresa "Beta" algumas foram mais relevantes e são detalhadas na seqüência.

Inicialmente, encontraram-se obstáculos na fase de obtenção das informações necessárias junto aos responsáveis pelas áreas respectivas. Talvez em função do ineditismo desse tipo de trabalho na empresa pesquisada, alguns dados demoraram a ser fornecidos ou o foram disponibilizados parcialmente, 
retardando a conclusão do estudo. Outro ponto que pode ter influenciado de forma negativa nesse aspecto é a natural "desconfiança" dos gestores das diversas fontes de dados quanto à sua destinação ou divulgação. Provavelmente, tal fato ocorreu pelo pesquisador ser pessoa alheia à organização. Esse problema foi diminuído através de reuniões com os envolvidos, em conjunto ou individualmente, que buscavam esclarecer/dirimir eventuais dúvidas que surgissem. Para tanto, foi fundamental a colaboração do principal diretor da empresa, que interferiu pessoalmente em diversas ocasiões.

Outra relevante dificuldade que surgiu diz respeito à indisponibilidade de determinadas informações no banco de dados utilizados ou nos outros controles internos da empresa. Nem todas as informações estavam à disposição no software ERP e algumas tiveram que ser obtidas com pesquisas em determinadas fontes ou através da elaboração de relatórios específicos e/ou adequação de relatórios previamente existentes. Também a defasagem de tempo entre os períodos de ocorrência e a contabilização e/ou levantamento de demonstrações contábeis (balancetes de verificação, balanço patrimonial e demonstração de resultados) contribuiu de forma significativa para retardar a coleta de dados. A conseqüência direta foi que o acesso aos balancetes e outras demonstrações passou a ser possível somente vários meses aos respectivos períodos de competência.

Um terceiro fator que dificultou a execução do trabalho foi que nem todos os indicadores listados no modelo são aplicáveis à empresa pesquisada. Isso ocorreu em virtude de que cada organização possui características próprias, oriundas tanto das atividades desenvolvidas (mercados abrangidos, segmentos específicos de atuação, tecnologia utilizada etc), quanto da estrutura de informações disponível (banco de dados e relatórios disponibilizados). Pelo mesmo motivo, alguns indicadores tiveram que ser desenvolvidos para adequar alguns pontos do modelo às peculiaridades da organização estudada.

Por último, cabe ressaltar que o usuário (ou o leitor do Mapa para Identificação de Potenciais Geradores de Intangíveis) deve considerar o aspecto da influência da estratégia da empresa quando da análise dos indicadores adotados, visto que um
Ativo Intangível pode ter seu valor influenciado pelos planos que a empresa tem para o mesmo. Para demonstrar tal influência, cita-se o caso da empresa pesquisada, em que a principal atividade é a fabricação de máquinas e equipamentos industriais para determinados segmentos. Atuando nesse mercado, em princípio a propriedade de direitos relacionados às patentes das máquinas fabricadas deveria se destacar como prioridade para a companhia. Entretanto, em conseqüência das dificuldades burocráticas do processo de patenteamento, a empresa optou por praticamente ignorar tal procedimento e comercializar seus produtos mesmo sem os registros cabíveis. Ocorreu isso porque, pelas características do segmento, tais Ativos Intangíveis (patentes) que poderiam constituir-se em diferencial mercadológico, passam a não ter tanta relevância para as finalidades da empresa, conforme o entendimento dos diretores.

O próximo tópico tece comentários relativos à avaliação do modelo, sua aplicação e os resultados mais importantes obtidos.

\section{CONCLUSÕES E SUGESTÕES PARA TRABALHOS FUTUROS}

Pelo sistemático acréscimo de importância dos ativos intangíveis no ambiente empresarial da atualidade, resta evidente a necessidade de sua identificação. As dificuldades de ordem prática encontradas ao identificar e avaliar os fatores intangíveis, principalmente pela subjetividade inerente, constituem-se pontos que podem desestimular ou tolher iniciativas nesse sentido. Porém, conforme evidenciado no modelo, é possível encontraremse alternativas que subsidiem a gestão dos ativos intangíveis.

Em relação ao objetivo principal, constatou-se que o mesmo foi atingido, de vez que a metodologia proposta permitiu identificar os potenciais geradores de intangíveis, contribuindo com o processo de análise e tomada de decisões empresariais. O emprego de vários indicadores, dispersos nas quatro perspectivas adotadas no modelo, proporcionou um retrato da situação da empresa em relação a diversos fatores intangíveis, geralmente não presentes nas demonstrações contábeis tradicionais. Além disso, os resultados alcançados foram satisfatórios 
em termos de possibilitar que os tomadores de decisão tenham um norte em relação aos componentes intangíveis do patrimônio da empresa pesquisada (pela identificação dos fatores geradores dos mesmos) e pela visualização das conseqüências das decisões de investimento a esses relacionadas (através das inferências oriundas das relações de causa e efeito).

Dentre os pontos positivos do modelo em lume, podem ser mencionados:

- adaptabilidade ao ambiente empresarial: em função da flexibilidade proporcionada pelo modelo, quando necessário os indicadores sugeridos na proposição inicial puderam ser adaptados ou substituído por outros, mais adequados à realidade da organização em tela. Por outro lado, os indicadores originais que não foram utilizados não comprometeram a potencialidade informativa do Mapa para Identificação de Potenciais Geradores de Intangíveis, em virtude de que não se aplicavam às características da empresa pesquisada;

- identificação de fatores intangíveis ou associados a ativos intangíveis: pela elaboração do Mapa para Identificação de Potenciais Geradores de Intangíveis foram evidenciados fatores intangíveis que não costumam ser divulgados através das demonstrações contábeis normalmente exigidas pela legislação e nem evidenciados nos controles internos das organizações;

- análise das informações geradas: identificar os ativos intangíveis proporcionou ao usuário dessas informações uma condição melhor de análise da empresa em lume, quer para finalidades endógenas (gerenciamento ou revisão de políticas internas nas áreas de projetos, vendas etc), quer para análises externas com as mais variadas finalidades.

Como deficiências do modelo apresentado, cabe que sejam listadas as seguintes limitações:

(a) não cobertura de todos os fatores intangíveis (pela multiplicidade de formas e possibilidades de ocorrência não é possível identificar por completo o conjunto de ativos intangíveis da organização); e (b) dificuldade de obtenção de alguns dados necessários para alimentar os indicadores selecionados (como o sistema de controles internos não dispunha de todos os dados requeridos, alterações ou adaptações tiveram quer ser efetuadas na forma de coleta para obtenção dos dados necessários para confeccionar o mapa proposto).

Finalmente, no sentido de contribuir com futuras pesquisas relacionadas ao tema enfocado sugerem-se, a seguir, algumas possibilidades. A primeira alternativa aventada é a de aplicar o modelo em outras empresas, verificando se os resultados obtidos são positivos ou não em termos de informações que contribuam com a escorreita gestão dos ativos intangíveis de tais entidades. Além disso, cabe averiguar a pertinência da utilização do modelo em entidades sem fins lucrativos, como autarquias públicas e organizações não-governamentais (ONG's). Recomendam-se, também, estudos no sentido de se tentar a "avaliação" de ativos intangíveis através de escalas, por intermédio de algum modelo que faça uso de Métodos Multicriteriais de Apoio à Decisão.

Por outro lado, talvez seja pertinente tentar eliminar as deficiências já mencionadas a respeito deste modelo. $\mathrm{O}$ aspecto de não cobrir todos os fatores intangíveis, mesmo considerando a grande dificuldade relacionada a isso, pode ser alvo de novos estudos que proporcionem uma abrangência maior em termos de outros indicadores aplicáveis à questão.

Igualmente, o fato de terem sido encontradas dificuldades para a obtenção dos dados necessários para alimentar os indicadores adotados requer que sejam estudadas alternativas para diminuir tal problema. Nessa direção, sugere-se a elaboração e/ou implementação de software específico que produza o Mapa para Identificação de Potenciais Geradores de Intangíveis, de forma periódica e vinculada aos sistemas de informações gerenciais à disposição no mercado. Outra opção que talvez seja viável é buscar a adaptação do software ERP atualmente utilizado na empresa estudada, uma vez que parte das fontes dos dados utilizados já consta do sistema empregado pela mesma. 


\section{REFERÊNCIAS BIBLIOGRÁFICAS}

ANTUNES, M. T. P. Capital intelectual. São Paulo: Atlas, 2000.

CATELLI, A.; SANTOS, E. S. Internet: desafio para uma contabilidade interativa. Revista Contabilidade \& Finanças, São Paulo, v.14, n.25, p.24-41, jan./abr. 2001.

IUDícIBUS, S. A contabilidade como sistema de informação empresarial. Boletim do IBRACON, Brasília, n. 245, p.7-9, out./nov. 1988.

JOHNSON, H. T.; KAPLAN, R. S. A relevância da contabilidade de custos. Rio de Janeiro: Campus, 1996.

KAPLAN, R. S.; NORTON, D. P. Organização orientada para estratégia: como as empresas que adotam o Balanced Scorecard prosperam no novo ambiente de negócios. Rio de Janeiro: Campus, 2000.

LEONE, J. S. G. Os vários tipos de demonstrações de resultados e a flexibilização da informação. Revista Brasileira de Contabilidade, Brasília, v.25, n.98, mar./abr. 1996.

LEV, B. Intangibles: management, measurement and reporting. Brookings Institution Press, 2001.
OLIVEIRA, A. B. S. Contribuição à formulação de um modelo decisório para intangíveis por atividade: uma abordagem de gestão econômica. São Paulo. 1999. 177f. Tese (Doutorado em Controladoria e Contabilidade) - Faculdade de Economia, Administração e Contabilidade, Universidade de São Paulo, São Paulo.

SILVA, A. S. et al. Custo de oportunidade. Revista Brasileira de Custos, São Leopoldo, v.1, n.1, 1999.

STEWART, T. A. A riqueza do conhecimento: o capital intelectual e a organização do século XXI. Rio de Janeiro: Campus, 2002.

WEBBER, A. M. A matemática da nova economia. HSM Management, São Paulo, n.20, maio/jun.2000.

WERNKE, R. Identificação de potenciais geradores de intangíveis. Florianópolis. 2002. 220 f. Tese (Doutorado em Engenharia de Produção) - Universidade Federal de Santa Catarina, Santa Catarina.

NOTA:

Endereço dos autores: RODNEY WERNKE

Av. José Acácio Moreira, 787 - Dehon Universidade do Sul de Santa Catarina 88704-900 - Tubarão-SC

\section{ANTONIO CEZAR BORNIA}

Universidade Federal de Santa Catarina Campus Universitário - Caixa Postal 476 88040-970 - Florianópolis-SC 